\title{
The Effects of Social Media on Literacy Development among Pupils in Junior High Schools in Ghana
}

\author{
Robert Andrews Ghanney \\ Department of Basic Education \\ University of Education, Winneba, Ghana \\ Theresa Antwi \\ Department of Basic Education \\ University of Education, Winneba, Ghana \\ Edmond Amoako Agyeman \\ Department of Basic Education \\ University of Education, Winneba, Ghana
}

\begin{abstract}
The study sought to investigate the effects of social media on literacy development among pupils in junior high schools particularly on their perception about the nature of literacy, identifying major social media network sites and their mass usage among pupils as well as the effects of social media and social networking sites on pupils' language learning and literacy development within the context of socio-cultural and social learning theories. To achieve the objectives of this study, a case study design was used which comprised the use of interviews to solicit pupils' responses on the effects of social media on literacy development. The population of the study consisted of all JHS pupils in the Asante-Akim South District in the Ashanti region of Ghana. A purposive sampling technique was used to select 25 pupils (14 females, 11 males) from three junior high schools. The data were analyzed using thematic analysis (qualitative content and document analyses), table with description and data triangulation. The findings showed participants' exposure to major social media tools and social networking sites such as Facebook, Short Message Services (SMS), WhatsApp, Twitter and You Tube likewise online practices such as chatting, blogging, watching movies, listening to audios, image sharing, and so on. The study in addition revealed that social media tools and online practices influence participants' reading skills and habits, writing skills and speaking in every way. This research recommends the strict application of Ghana Education Service rules and parental guidance on electronic devices usage in schools, homes and the promotion of social media networks for educational purposes.
\end{abstract}

\section{INTRODUCTION}

Literacy has been defined and explained in numerous ways and from differing angles depending on the transformation language studies that have gone through. Moll (1994; p. 201) as cited in Kasper (2000), defines literacy as "a particular way of using language for a variety of purposes, as a socio-cultural practice with intellectual significance." Nevertheless, studies conducted on literacy instruction have emphasized the recognition and enhancement of the thought processes as well as ways to read printed texts (Hull \&Moje, 2011). UNESCO (2006) explains that literacy in the late nineteenth century has been perceived as being the skill to recognize text in reading and writing whereas its general meaning of being an expert or elite in a specific line of study is maintained. It basically refers to a set of observable skills especially relating to one's intellectual ability to read and write (UNESCO, 2006). 
Our educational experiences are largely composed of our abilities to read, write, speak and decipher information. For this reason, reading and writing instruction undoubtedly becomes the vital means through which young children acquire literacy (Antilla, 2013). In light of these, one can say that literacy development is very crucial in the academic lives of students. It is therefore arguably true that the rate at which students can read and write highly determines their acceptability in the educational society. Parents, countries, individuals, stakeholders are all striving harder to get access to the available literacy as early and fast as possible for their wards, citizens.

\section{STATEMENT OF THE PROBLEM}

There have been series of arguments on various platforms and media as to the influence social media have on society and specifically, its effects on major literacy skills. Some studies have revealed a fall in standard language use and inadequate time for literacy instruction and acquisition as a result of the mass usage of social media and social networks (Rouis, Limayem\&Salehi-Sangari, 2011; Sani\&Bature, 2014; Sarkar, Agarwal, Gosh \&Nath, 2015). Research of the same kind have also shown that social media foster human interaction which is also a perfect requisite for language learning and literacy acquisition (Sharma \&Mahavidhalaya, 2015). In as much as series of studies are showing the relationship between social media and literacy development, other studies on the other hand have also indicated that social media and social networks have no bearing as far as literacy development and learning are concerned (Ahn, 2011; Bouhnik \&Deshen, 2014).

There have been countless efforts by stakeholders, governments, teachers, counsellors and parents to improve literacy among JHS pupils in Ghana. Regardless of these attempts to develop literacy, pupils are still faced with some manner of literacies as they constantly associate themselves with the activities and practices in the society.

The younger generation is tagged as being potential and future writers. This is because many of them demonstrate series of writing qualities and skills especially when it comes to narratives and other forms of essay writing. However, these promising and emerging writers find their writing skills and qualities in jeopardy as a result of their constant encounter with social media and other social networking sites (SNS) like Facebook, Twitter, and YouTube.

\section{PURPOSE OF THE STUDY}

The purpose of this study was to investigate the influence of social media on literacy development among JHS pupils in the Asante- Akim District.

\section{OBJECTIVES OF THE STUDY}

To achieve the purpose of the study, the following research objectives were proposed to guide the study:

1. to investigate the forms of social media activities and practices pertaining to JHS pupils' literacy in the Asante-Akim District.

2. to find out the influence of social media on literacy development among JHS pupils in the Asante-Akim District.

\section{RESEARCH QUESTION}

To what extent do social media influence literacy development among JHS pupils in the AsanteAkim District? 


\section{RELATED LITERATURE}

The review of literature, delve into the theoretical, conceptual frameworks and empirical review of the study.

\section{THEORETICAL FRAMEWORK OF THE STUDY}

\section{Socio-cultural Theory and Literacy Development}

From time immemorial, theories of many kinds have been advanced to aid diverse learning styles. Nonetheless, the theory underpinning this research operates within Vygotsky's (1978) sociocultural theory of language learning as well as Bandura's (1971) theory of social learning.

Advocates operating within the boundaries of such philosophy argue that people's thought processes, state of emotion and mental states have no bearing on their changes in behaviour. In the view of these theorists, they contend that even the most complex form of human learning could be explained based on the basic principles of conditioning (Microsoft Student Encarta, 2009). Nevertheless, Vygotsky (1978) and Bandura (1971) proved otherwise in their assertion which described the relationship between learners' environment and their abilities to learn.

According to Barnard and Campbell (2005), Vygotsky believed "that human learning cannot be understood independently from the social and cultural forces that influence individuals, and that sociocultural interactions are critical to learning." To them, Vygotsky was confident that there seemed to be an apparent relationship between individuals and their environment.

Bandura (1971) opines that the learners' surroundings play a crucial role in the learning process when he states that, "environments are loaded with potentially lethal consequences that befall those who are unfortunate enough to perform dangerous errors". According to him, learning can occur through modelling. He confirms this by saying that most of the behaviours people exhibit are learned either intentionally or involuntarily through the sway of examples. Basically, some of the key concepts in Bandura's social learning theory is based on the idea of 'Observational Learning' (Bandura, 1971; Smith \& Berge, 2009), which contends that human beings often cannot learn for themselves (Smith \& Berge, 2009).

\section{Literacy Development}

Being literate therefore is a term used to describe a wide range of different learning behaviours, ranging from the skill to act on reading and writing to the knowledge of some related body of literature (Bormuth, 2003).

Coiro (2003; p.460) confirms, "the nature of literacy is rapidly changing as new technologies emerge." Regardless of the many mismatches concerning the definition and scope of literacy, Lankshear and Knoebel (2008) maintain that, "whatever literacy is, it has something to do with reading." They strongly opine that literacy no matter how is deeply rooted in some practices primarily reading and writing. Nevertheless,literacy building, literacy instruction and literacy acquisition in modem times havegone beyond the traditional notion of reading and writing to occupy abilities to manipulate multimedia (Van Daal\&Sandvik, 2012).These new technological avenues to communication include the various Instant Messaging applications (IMs) that have emerged by virtue of the internet. Sewe (2014) as cited in Vural (2015) reveals that the social media also known as Social Networking Sites (SNS) such as Facebook, Twitter, Instagram, MySpace, YouTube, We Chat and IMO have all famously gained roots in the daily lives and practices of the students we have in our classrooms today. 


\section{Effects of Social Media on Literacy Development}

Relatively, a huge number of factors have influenced literacy development over the years. Even before the advent of technology various skills and abilities needed or acquired to read and write were highly still manipulated either by external or internal factors. Nevertheless, as individuals and societies pass through changing times (digital age/technological era), their conventional way of viewing literacy is modified hence their literacy skills. For instance, the mass usage of the internet especially with social networking sites (SNS) and social media practices such as Facebook, Twitter, Instagram, Skype and many others have gained grounds in the everyday literacy lives and skills of young ones (Sewe, 2014 as cited in Vural, 2015).

The impacts of social media are evidential almost throughout all literacy skills. Writing mistakes such as wrong grammar is often rampant in pupils' writing because pupils see social media platforms as digital communities where Standard English use is irrelevant as suggested by (Sani \& Bature 2014; Sarkar, Agarwal, Gosh \& Nath 2015).Young ones are often fond of using smileys, emoticons, phonetic replacement games learned from and used on social media platforms to proof points in formal writings (Craig, 2003; Sani\&Bature, 2014; Sarkar, Agarwal, Gosh \&Nath, 2015).Coiro (2003) opines that internet reading are mentally challenging because online texts contain certain features and hyperlinks which may require additional processing of comprehension skills on the part of the reader. This means contents and materials read on digital online platforms hinder users' evaluation skills. Adams (2011) and Craig (2003) maintain that instant messaging and certain social media features more or less threaten reading and fluency skills among young people. This means that social media and social networking sites in general can act negatively on pupils' reading fluency skills.

The review indicated that the impact of social media on young people's ability to read and write is not invisible or one-sided but rather a two-edged sword. This shows that research on the subject of literacy development vis-a-vis social media influence, is not conclusive. This is therefore a notification enough for further research into the subject.

\section{Research Design}

\section{METHODOLOGY}

In order to achieve the purpose of this study, a case study design was adopted for it. The qualitative approach was employed because interviews, observation and documentation were used. Case study is a form of research that studies characteristics of individual units such as clique, class, school or community (The Commonwealth Diploma in Youth Development, 2007). It is a comprehensive analysis of a single or multiple events, settings, programs, groups, or one or more individuals (Owu-Ewie, 2011). The study shows the influence of social media on literacy development.

\section{Population of the Study}

The target population for the study comprised all Junior high school pupils in the Ashanti region whereas the accessible population involved all junior high school pupils in the AsanteAkimSouth District. The district has 14 circuits and 81 junior high schools out of which 69 are public and 12 private schools (Asante-Akim South District Educational Directorate, 2014). According to the Asante-Akim South District Educational Directorate report (2014), the total enrolment for junior high schools in the district is 8,055 (public $=6950$ [boys $=3804$, girls $=$ $3146]$; private $=1105$ [boys $=510$, girls $=595]$ ).

\section{Sample and Sampling Technique}

The sample was chosen from the Asante Akim South District in the Ashanti region of Ghana. Quota sampling technique was used to select five (5) circuits for the study; however, simple 
random sampling technique was adopted to further choose the two (2) main participating circuits because the Asante Akim South District is already composed of both public and private schools. Quota sampling technique is a non-probability sampling technique whereby the researcher selects while structuring the study how many people with which characteristics are to form the sample (Family Health International, 2012).

Three (3) schools (public schools = 2 [1 urban public school; 1 rural public school]; private school = 1) were randomly selected using simple random sampling technique from the two (2) circuits in the district because the researcher wanted every school to have an equal chance of getting selected. Simple random sampling technique is a probability sampling technique, which offers a fair way to select a sample making generalization easy and flexible (Owu-Ewie, 2011).

Fifty (50) pupils were further selected using the same simple random sampling technique; however, twenty-five (25) pupils of which fourteen (14) were females (urban public school = 8 females; rural public school $=2$ females; private school $=4$ females) and eleven (11) males (urban public school $=6$ males; rural public school $=3$ males; private school $=2$ ) were purposively selected from the total number for the study. In all, a total of twenty-five (25) pupils from junior high schools were selected from the three (3) schools in the district. This comprised fourteen (14) females and eleven (11) males. The pupils chosen from the sampled schools were all in junior high school. At this stage, majority of them must have been exposed to social media where pupils practiced their various literacy skills.

\section{Demographic Information of Participants}

The ages of all the twenty-five (25) participants ranged between thirteen (13) and twenty (20) years. Participants' ages were relevant in order to establish conformity between the proposed age for junior high school by the Ghana Education Service and that of respondents used for the study. Again, participants ranging between the disclosed ages were selected because they were observed or seen as having regular encounter with a number of major social media platforms such as Facebook, WhatsApp, Twitter, SMSs (Short Message Services) and electronic and digital communication devices such as mobile phones and computers. The demography of participants confirms that nearly half of children within the ages of eight (8) and seventeen (17) years have access to the internet and social media platforms exactly as maintained by Dowdall (2009) as cited in Cooper, Doonan and Fawcett (2012).

\section{Instrumentation}

The instruments adopted for the study were interview guide (semi-structured), close participant observation guide and documentation. The items in the interview and observation guides were constructed to find out social media effects on pupils' literacy development. Each item on the guide was constructed to reflect the various literacy skills which pupils are required to acquire as specified in the English language syllabus for junior high schools. The framework as proposed by ECAR Research Study 8 (2008) drove the interview and observation guides development.

\section{Validity}

In ensuring trustworthiness of the instruments, experts, supervisors, English language teachers, colleagues and pupils (participants) were consulted for suggestions, before they were earned out as proposed by Anderson and Morgan (2008). Data triangulation was also done to check for validity of the instruments. 


\section{Data Gathering Procedure}

The semi-structured interview guide designed to find out the effect of social media on literacy development was used to interview all pupils who participated in the research. Series of conversations between pupils and peers, pupils and teachers and pupils and parents were also closely observed. Again, the researchers had the opportunity to examine pupils' social media contents on their mobile phones as well. Pupils' responses during the interview helped the researchers to gather information on their literacy behaviours and their frequent participation in social media activities.

\section{DATA ANALYSIS}

The researchers went through pupils' (participants') responses, and particular set of behaviours were closely observed and recorded. Participants were coded whereas their responses to interview questions and behaviours recorded were all subjected to thematic analysis, which mainly comprised both qualitative content, and document analyses. Data gathered from the documents were presented using table with descriptions to be in line with the themes already established.

\section{Data Presentation and Analysis of Research Question}

Research question: To what extent do social media influence literacy development among JHS pupils in the Asante-Akim District?

The responses given by participants during the interview were tabulated in a table with descriptions. The researchers also documented some observed behaviours as evidenced in pupils' official documents. The obtained findings were collected under the themes of negative effects and positive effects of social media on literacy development.

\section{Negative and Positive Effects of Social Media on Literacy Development}

Participants were asked in the interview to describe some negative and positive effects of using social media and social networking sites in relation to their literacy development. The results of the interview were used to create operational definitions for coding categories in Table 1. 
Table 1: Operational definition for coding categories

\begin{tabular}{cl}
\hline Negative Effects & Definitions \\
\hline Writing mistakes & \\
Grammatical errors & $\begin{array}{l}\text { People use a lot of incorrect tenses and wrong sentence } \\
\text { construction on social media and other related social network } \\
\text { sites. }\end{array}$ \\
Wrong spelling & $\begin{array}{l}\text { Wrong spelling and incorrect wordings are engulfing the } \\
\text { internet. Individuals are also responding to these spelling and } \\
\text { wording patterns by copying and using them in many social } \\
\text { media platforms and social networking sites }\end{array}$ \\
Wrong punctuation & $\begin{array}{l}\text { Individuals do not give much regards to accurate and correct } \\
\text { forms of punctuation. Incorrect abbreviations, formulated } \\
\text { acronyms, unnecessary commas, semicolon, colon, etc. are all } \\
\text { forms of wrong punctuations social media users are using on } \\
\text { social media and social networking site platforms }\end{array}$
\end{tabular}

Symbol/Emoticons/ Social media and social networking site users often use a lot of Short-Hands symbols, icons and emoticons in their chats. They also stick to many short-hand texts in their online write ups on manysocial media platforms.

\section{Reading barriers}

\section{a. Lack of evaluation skill}

\author{
b.Meaningless \\ reading
}

\section{c. Fluency}

Speaking/speech challenges

Less speech
Individuals lack the judgemental skill when it comes to online information and their sources. Social media users do not attach any seriousness to the things they read on the internet. Those who do, see whatever information surfing social media platforms as true and reliable without cross checking.

Social media and social networking users often do not read online contents for meaning. Individuals on social media platforms read online contents for reading sake only leaving out the purpose of such contents.

Social media activities do not encourage users' reading fluency skills due to the unique nature of some of the texts and features inherent in them.

Social media and social networking sites users often do not engage in oral conversation or interaction with people. Social media platforms have minimized human physical speech interaction.

\section{Positive aspects}

(benefits of users)

a. Communication

\section{Definitions}

Social media enhances communication skills among young people. This is because, through social media, young people also get the opportunity to meet and interact with people and other groups on the platform. 


\section{b. Motivation}

c. Vocabulary development

d. Creativity

e. Self-peer evaluation

f. Resources
Individuals are motivated to write and read more on social media platforms since it is the only avenue through their views can be heard.

Social media has added a lot in terms of addition of new words among users. People are now learning new words through social media platforms and other social networking sites.

Social media has touched creativity and imagination skills among users. People now create their own stories and others have got their own way of inventing writing styles.

Social media has enabled users to measure their level of reading and writing skills.

People have now become more resourceful because social media now provides array of language learning platforms where users can build their reading and writing skills.

The theme of the negative effects of using or participating in social media and social networking sites is explained in detail in Table 2: 
Table 2: Categories, Frequencies and Sample Expressions Related to the Theme of Negative Effects

\begin{tabular}{lll}
\hline Categories & N & Sample Expressions
\end{tabular}

1. Writing Mistakes

a. Wrong spelling

M Pupils on social media use too many wrong spellings and incorrect wordings on social media platforms. Since these errors are overlooked, they transfer them into official write ups.

b. Wrong punctuation

c. Symbols/emotion s/short-hands

2. Reading Barriers

a. Lack of evaluation $\quad M$ skill

b. Fluency

3. Speaking/speech challenges

a. Less speech

b. Speech jargons
M Incorrect punctuations such as incorrect abbreviations, formulated acronyms, unnecessary commas, semi-colon, colon, etc. have taken over social media platforms thereby affecting literacy skills among pupils in the classroom.

M Pupils on social media platforms often exhibit certain text styles such as short hands, symbols and emoticons in their essays.

M Information read on the internet and on other social media platforms properly evaluated. Pupils often fail to think through or verify information sources. They either trust information source or refute it without cross checking.

M This is because social media platforms contain unique characters that are quite challenging and difficult to understand.

M Social media and social networking sites have minimised oral interactions and speech dialogues among pupils and other groups. Pupils are no longer interested to have physical conversations with others because they see social media platforms as their agent of socialization.

M Pupils are now using new sets of informal language and other terms in their everyday utterances. Social media is increasingly promoting alien words among pupils today.

\section{Note: $\mathrm{N}$ shows the number of participants; M shows majority of participants}

\section{Writing Barrier}

Majority of participants interviewed said that they do make many grammatical mistakes and other construction errors on social media platforms. However, they disclosed that they do not show greater concerns about the corrections of tenses and sentences when chatting on social media. They said that as long as there is meaning in whatever they want to write, language errors become irrelevant to them. Sample of participants' responses are captured below:

1. "I make a lot of writing mistakes in my online chats with people."

2. "Sometimes I use 'have' for 'she', 'he' and 'it' in many of the chats."

3. "1 also often choose 'has' for 'they'."

4. "Grammatical mistakes are inevitable on Facebook, WhatsApp and SMS platforms but as long as there is meaning in whatever has been written, these mistakes become less influential." 
The responses given prove that participants make a lot of grammatical mistakes on social media platforms. These writing mistakes according to the respondents occur due to oversight, haste or the nature of some mobile devices. The responses participants gave confirm that writing mistakes such as wrong grammar are often rampant in pupils' writing because pupils see social media platforms as digital communities where standard English use is irrelevant as suggested by Sani and Bature (2014) and Sarkar, Agarwal, Gosh and Nath (2015).

\section{Wrong spelling}

Findings from the study showed that wrong spelling and incorrect wording are rampant on social media platforms. Majority of participants said that they do commit a lot of spelling mistakes. They also accepted that their mode of wording on social media platforms often lack quality. The researchers saw that such writing errors occur because participants sometimes have no knowledge as to the correct spellings of such words. Therefore, they pick any close spelling of such words up from digital platforms.

Others also said that the spell-checkers as preloaded in some digital keywords cause these wrong spellings and incorrect wordings. Meanwhile, some said oversight and haste during typing account for such writing errors. Sample of participants' responses are shown below:

1. "I make many spelling mistakes in my Facebook chat."

2. "I don't get all words correctly spelled when chatting."

3. "You can't resist wrong spellings on WhatsApp."

4. "Sometimes, the spelling options can even spell words wrongly and suggest them for use".

5. "Many of us depend on spell-checkers because some words are difficult to spell.

So wrong spellings are bound to happen when chatting on "WhatsApp and Facebook."

\section{Wrong punctuations}

It was concluded that users use many punctuation errors on social media platforms and social networking sites. Majority of participants said they use many inappropriate punctuation marks on digital online platformslike WhatsApp, Facebook and Twitter. They disclosed that the use of wrong punctuations such as illegitimate forms of abbreviations, 'invented' acronyms and others are either intentional or unintentional. However, they claimed that wrong punctuations are hard to prevent due to haste and forgetfulness on the part of the user. They also said that the nature of some social media platformscall for intended wrongful punctuations in order to get one's message across. Below are sample of responses given by participants:

1. "I don't normally use full stops in my chats but I do use a lot of abbreviations."

2. "It's not all the time that I capitalize words when chatting with people on WhatsApp."

3. "The only punctuation mark I often use when chatting on any platform is question mark."

4. "Punctuation marks consume text space so I avoid them on platforms such as Twitter where users are given limited amount of words or characters."

5. "Honestly, I sometimes misuse commas, colons and semicolons and marks."

6. "I have no idea how some of the punctuation marks are used in sentences."

These responses confirm that the power of literacy is determined through writing and as such there is the need for writers to recognize graphic features such as punctuation, segmentation and capitalization (Sani \& Bature 2014). 


\section{Symbols/Emoticons and short-hand text styles}

It was concluded from the findings that users on social media platforms and other related social networking sites use a lot of symbols, emoticons and short hand text styles to carry their messages across on such platforms. Symbols and emoticons used on social media platforms carry meanings and explain the mood of users. In the same way, users stick to short hand text styles on digital platforms in order to shorten their message and thoughts.

Majority of participants said in the interview that they use different kinds of symbols, emoticons and short hands text styles to make their conversation on digital platforms easy and also to prove a point. Others said that the nature of some platforms demands that users used short hand text styles. These are samples of their responses:

1. "1 use short hand and symbols all the time because Twitter allows few words."

2. "Sometimes emoticons do all the talking."

3. "I stick to symbols and emoticons because they make chats interesting."

4. "We are use short hands on Facebook and WhatsApp because they are simple to use and makes the chat very quick."

5. "I don't remember the last time I wrote words or sentence in full. I always use short hands and symbols because it makes the chat lively."

6. "Too much words make the chat boring. That's why I use symbols and short hands."

These responses confirm that young ones are often fond of using smileys, emoticons, phonetic replacement games learned from and used on social media platformsto proof points in formal writings (Craig, 2003; Sani\&Bature, 2014; Sarkar, Agarwal, Gosh \&Nath, 2015

\section{Reading barriers}

It was concluded that social media platforms and social networking sites do have negative effects on pupils' reading skills and reading habits. The researchers identified lack of evaluation skills, and fluency as the possible side of effects of social media and social networking sites as far as users' reading skills are concerned.

\section{Lack of evaluation skills}

The findings showed that users on social media platforms and social networking sites do not exhibit adequate judgmental skills. It was realised that contents read across social media platforms and readers or users do not properly decode other related social networking sites such as WhatsApp, Twitter, SMS and Facebook. In the interview, majority of participants said that Facebook and WhatsApp are their only source of information. They disclosed that they rarely refute information often read on these platforms unless such information are widely disregarded by the heavy public. Participants also said that they stick to contents read across social media platforms because access to other sources of information for verification is also quite expensive. These are sample of participants' responses:

1. "Facebook is my source of information. People give me updates on current trends of issues."

2. "Information sent across WhatsApp and Facebook are always genuine."

3. "I depend a lot on news surfing Facebook and WhatsApp because I don't have the money to buy any national newspaper."

4. "Information will be always information no matter where the source."

5. "Facebook and WhatsApp have made access to information easier and less expensive."

The response participants gave suggests that they do not or have not been adequately evaluating contents and materials read on social media platforms. These responses agree with Coiro (2003) who opines that internet reading are mentally challenging because online texts 
contain certain features and hyperlinks which may require additional processing of comprehension skills on the part of the reader. This means contents and materials read on digital online platforms hinder users' evaluation skills.

\section{Fluency}

The findings revealed that social media and social network activities have negative bearings on users' reading fluency and accuracy. Social media platforms and social networking sites come with so many different text features and other forms of writing styles which encourage reading slips, errors and mistakes. These text styles stand in the way of users' reading fluency skills.

Majority of participants said in the interview that they are sometimes unable to read the way they want to. They disclosed that certain text features and symbols such as emoticons, smileys and other forms of lettering often used in social media platforms make reading very difficult to flow. They also confirmed that some users intentionally mingle letters, invert words and sentences on digital platforms like Facebook, WhatsApp and Twitter only to confuse readers and to slow or pin fast and fluent readers down. Participants revealed that excessive short hand text styles, wrong grammar, punctuation errors and improper sentence constructions as used in many social media platforms also sometimes prevent them from enjoying their reading. Below are samples of participants' responses:

1. "Some emoticons are tricky and difficult to read."

2. "Short hand writers sometimes make reading WhatsApp chat very trouble."

3. "No matter how fast or fluent one's reading is, you definitely have to slow down when you come across some symbols, emoticons and short hands for the first time in your chat."

4. "People often use mixed-up sentences and words on WhatsApp and Facebook only to try good readers."

5. "Reading becomes quite challenging when there are too many poor incorrect sentences and unnecessary punctuations."

The responses given indicate that participants indeed encounter reading challenges on social media platforms and social networking sites. These responses attest to Adams (2011) and Craig (2003) who maintain that instant messaging and certain social media features more or less threaten reading and fluency skills among young people. This means that, social media and social networking sites in general can act negatively on pupils' reading fluency skills.

\section{Speaking/speech challenge}

It was concluded from the findings that the presence of social media and social networking sites has badly affected oral interactions and other forms of verbal utterances. It was revealed that these platforms do not encourage eloquence and speech fluency. It was realised that digital online platforms such as Facebook, WhatsApp and others have all resulted in less speech' and frequent 'speech jargons'.

\section{CONCLUSION}

The findings showed participants' exposure to major social media tools and social networking sites such as Facebook, Short Message Services (SMS), WhatsApp, Twitter and You Tube likewise online practices such as chatting, blogging, watching movies, listening to audios, image sharing, and so on. The study in addition revealed that social media tools and online practices influence participants' reading skills and habits, writing skills and speaking in every way. 


\section{RECOMMENDATIONS}

The recommendations are grouped into the following: Recommendations to Ghana Education Service (GES), Parents and Guardians, and Counsellors.

\section{Recommendations to Ghana Education Service (GES)}

This research recommends the strict application of Ghana Education Service rules. Management of Junior High Schools in Ghana, including the Directors of Education, Headmasters and Headmistresses, Form Masters and Mistresses, and Teachers should enforce the rule for the students not to use phones and other social media that will go against their studies in schools.

\section{Recommendations to Parents and Guardians}

- Parents and guardians should not allow children to sleep with their devices in their bedrooms, including smartphones, ipads, televisions and computers. This will enable children to have adequate sleep so as to stay alert for the following day's activities in school.

- Parents and guardians should select programmes that are likely to facilitate development and health in children, such as reading, teaching, respect for elders, telephone manners and the use of appropriate courtesies on doing things, these would enable children to use the media to learn and be creative and share their experiences. Parents and guardians should watch these programmes with their children and wards.

- Parents should discourage children from watching entertaining programmes on the media while doing their homework or studying or eating.

\section{Recommendations to Counsellors}

- Counsellors should help students in the Asante-Akim District on the advantages and disadvantages on the use of social media on their learning by giving them a talk. For example, the use of media-free environments can easily influence students intocyberbullying, sex, and communications that can affect personal privacy and wellbeing. However, when used positively can improve students' academic achievement, especially with regard to use online software in the teaching and learning of concepts and the pronunciations of words.

- Counsellors should make it a practice of helping students to make it their habit not to go against the rules set for them on the use of social media. They should be each other's keeper and as a matter of urgency report their peers who flout the rule to the Headmaster or Headmistress for the necessary punishment.

- Counsellors should help parents and guardians through talk shows during Parent Teacher Association (PTA) meetings on how to control their children at home on the type of media and how much media are appropriate for their children and wards.

\section{References}

Adams, M. J. (2011). Technology for developing children's language and literacy: bringing speech recognition to the classroom. New York, NY: The Joan Ganz Cooney Center at Sesame Workshop.

Ahn, J. (2011). The effect of social network sites on adolescents' social and academic development: Current theories and controversies. Journal of the American Society for Information Science and Technology.62(8), 1435-1445. New Jersey: John Wiley \& Sons, Inc.

Anderson, P., \& Morgan, G. (2008).Developing tests and questionnaires for a national.Assessment of educational achievement. Washington DC: World Bank.

Antilla, J. A. (2013). The effects of early literacy development on academic success in the educational setting and implications for educational leaders and teachers (Master's thesis). Retrieved from: $\underline{h t t p: / / w w w . n m u . e d u}$, on $4^{\text {th }}$ July, 2016 
Bandura, A. (1971). Social learning theory. New York City: General Learning Press. Pp. 1-8.

Barnard, R., \& Campbell, L. (2005). Sociocultural theory and the teaching of process writing: The scaffolding of learning in a university context. The TESOLANZ Journal, 13, 76- 88. Hamilton, New Zealand: Waikato University Press. Retrieved from: http://researchcommons.waikato.ac.nz

Bouhnik, D., \&Deshen, M. (2014).WhatsApp goes to school: Mobile instant messaging between teachers and students. Journal of Information Technology Education: Research. 13, 217-231. California: Informing Science Institute

Bormuth, J. R. (2003). Reading literacy: Its definition and assessment.Reading Research Quarterly,9(1): 7 - 66. London: Wiley \& International Reading Association.

Coiro, J. (2003). Exploring Literacy on the Internet. Reading comprehension on the Internet: Expanding our understanding of reading comprehension toencompass new literacies. The Reading Teacher,5(5(5), 458-464. Oxford: Oxford University Press.

Cooper, S., Doonan, K., \& Fawcett, N. (2012).Enterprising technology>: Using 4G technology to improve literacy skills.Retrieved from: http://escalate.ac.uk, on September 11, 2016.

Craig, D. (2003). Instant messaging: The language of youth literacy. The Boothe Prize Essays 2003. Pp. 116-133. Stanford, CA: Stanford University Press.

Family Health International (2012).Qualitative research methods: A data collector's field guide. London: Sage Publications

Hull, G. A., \&Moje, E. B. (2011).Understanding language: what is the development of literacy the development of? California: Stanford University Press

Kasper, L. F. (2000). New Technologies, New Literacies: Focus Discipline Research and ESL Learning Communities. Language Learning \&Technology.4(2), 105. Retrieved from: http://www.llt.msu.edu/vol4num2/kasper/

Lankshear, C. J., \&Knoebel, M. (2008)."Introduction: Digital Literacies: Concepts, Policies and Practices'. In Colin and Michele (Eds.), Digital Literacies: Concepts, Policies and Practices, 1-6, 249. New York: Peter Lang Publishing, USA.

Microsoft Encarta Dictionary (2009)."Literacy". Microsoft Student 2009 [DVD], Redmond, WA: Microsoft Corporation, 2008.

Owu-Ewie, C. (2011). Learn to do research: An introduction to research methods. Winneba: University of Education, Winneba. Pp.8

Rouis, S., Limayem, M. \&Saheli-Sangari, E. (2011). Impact of Facebook usage on students' academic achievement: Roles of self-regulation and trust. Electronic Journal of Research in Educational Psychology. 9(3), No. 25, 961994. Almeria: University of Almeria, Spain. ISSN: 1696 - 2095

Sani, I., \&Bature, S. (2014). The Impact of Social Networks on ESL Undergraduate Students' Writing in Nigeria.Arts and Social Sciences Journal, 5(2), 1 - 3 . Nigeria: OpenAccess, Creative Commons Attribution License.

Sarkar, A., Agarwal, S., Ghosh, A., \&Nath, A. (2015). Impacts of social networks: A comprehensive study on positive and negative effects on different age groups in a society. International Journal of Advance Research in Computer Science and Management Studies.J(5), 177-190. India: IJARCSMS.

Sharma, N., \&Mahavidhalaya, S. M. (2015). Impact of social media on English language: A review. International Journal of English Language, Literature and Humanities. 3(3), 532 - 536. Bhopal, India: Support Foundation.

Smith, M. \& Berge, Z. L. (2009).Social learning theory in second life.MERLOT Journal of Online Learning and Teaching, 5(2), 439-445. California: MERLOT, California State University.

The Commonwealth Diploma in Youth Development (2007).Introduction to methodology of socicd investigations: Region specific module 14. Accra: Institute of Adult Education, University of Ghana, Legon. Pp. 13 $-14$.

UNESCO (2005). Why literacy matters. Education for All (EFA) Globed Monitoring Report.UNESCO. Pp. 137-138 Van Daal, H. P. \&Sandvik, J. M. (2012).The Effects of Multimedia on Early Literacy of Children at Risk: A MetaAnalysis.An EETC presentation given at the University of Stavanger. Retrieved from: http://www.lesesenteret.no Vural, O. F. (2015). Positive and negative aspects of using social networks in higher education: A focus group study. Educational Research and Reviews. 10(8), 1147 - 1166. Ohio: Open Access, Academic Journals. 
Vygotsky, L. S. (1978). Mind in society: The development of higher psychological processes. Cambridge, Mass: Harvard University Press. Pp. 79-91. 